\title{
Food insecurity and household eating patterns among vulnerable American-Indian families: associations with caregiver and food consumption characteristics
}

\author{
Britta Mullany*, Nicole Neault, Danielle Tsingine, Julia Powers, Ventura Lovato, \\ Lena Clitso, Sheree Massey, Adrienne Talgo, Kristen Speakman and Allison Barlow \\ Johns Hopkins Center for American Indian Health, Johns Hopkins Bloomberg School of Public Health, \\ 621 North Washington Street, Baltimore, MD 21205 , USA
}

Submitted 22 August 2011: Final revision received 5 April 2012: Accepted 18 April 2012: First published online 5 July 2012

\begin{abstract}
Objective: To identify factors associated with food insecurity and household eating patterns among American-Indian families with young children.

Design: Cross-sectional survey among households with young children that were receiving emergency food services. We collected information on food insecurity levels, household eating patterns, experiences with commercial and community food sources and demographics, and used multivariate regression techniques to examine associations among these variables.

Setting: Four Southwestern American-Indian reservation communities.

Subjects: A total of 425 parents/caregivers of young children completed the survey.

Results: Twenty-nine per cent of children and $45 \%$ of adults from households participating in the survey were classified as 'food insecure'. Larger household size was associated with increased food insecurity and worse eating patterns. Older respondents were more likely than younger respondents to have children with food insecurity (relative risk $=2 \cdot 19, P<0 \cdot 001$ ) and less likely to have healthy foods available at home (relative risk $=0 \cdot 45, P<0 \cdot 01$ ). Consumption of food from food banks, gas station/convenience stores or fast-food restaurants was not associated with food insecurity levels. Respondents with transportation barriers were 1.46 times more likely to be adult food insecure than respondents without transportation barriers $(P<0 \cdot 001)$. High food costs were significantly associated with greater likelihoods of adult (relative risk $=1 \cdot 47, P<0 \cdot 001$ ) and child (relative risk $=1 \cdot 65, P<0 \cdot 001$ ) food insecurity.

Conclusions: Interventions for American-Indian communities must address challenges such as expense and limited transportation to accessing healthy food. Results indicate a need for services targeted to older caregivers and larger households. Implications for innovative approaches to promoting nutrition among American-Indian communities, including mobile groceries and community gardening programmes, are discussed.
\end{abstract}

Keywords American Indian Food insecurity Early childhood
Food insecurity is defined as limited or uncertain availability of nutritionally adequate and safe foods and limited or uncertain ability to acquire foods in socially acceptable ways' ${ }^{(1)}$. According to the US Department of Agriculture, $14 \cdot 7 \%$ of US households experienced food insecurity in 2009. Rates of food insecurity were substantially higher for households with low income, single parents and ethnic minorities ${ }^{(2)}$.

American Indians (AI) have the lowest health, economic and social status of any ethnic or racial group in the USA; they also have the highest food insecurity rates in the country. Recent data suggest that approximately twice as many American-Indian (AI) households with children are food insecure as non-AI households ${ }^{(3)}$. Diet and activity patterns of AI have changed dramatically in the past three generations. Traditional foods, such as wild game, nuts, fruits and berries, have been replaced by less diverse, processed commodities and convenience foods ${ }^{(4,5)}$. Thus, in rural AI communities, access to healthy, nutritious foods is a major barrier precipitating widespread public health effects from poor nutrition and food insecurity ${ }^{(6,7)}$. Among AI children, obesity has rapidly emerged as one of the most serious public health problems facing their generation $^{(8)}$. A study of over 11000 AI children found that $47 \%$ 
of 5-year-old boys and $41 \%$ of 5-year-old girls were overweight, and $24 \%$ of children were obese ${ }^{(9)}$, approximately twice the national average ${ }^{(10)}$. The health risks of obesity, especially CVD and diabetes, are profound for AI populations. CVD, which used to be rare among AI, now exceeds rates in other US populations and is more often fatal $^{(11)}$. Diabetes rates are threefold higher among AI populations than the general US population ${ }^{(12)}$, and over half the increase in mortality rate for $\mathrm{AI}$ in the past two decades has been attributed to diabetes ${ }^{(13)}$.

The concurrent existence of food insecurity and obesity has been examined in several US populations. Some studies indicate that food insecurity drives the purchase and consumption of cheap, energy-dense foods to get the most kilojoules when money is limited, as well as overeating when foods become available after periodic food shortages ${ }^{(14-18)}$. Food insecurity has also been associated with family factors such as suboptimal infant feeding practices and non-adherence to child feeding recommendations, which combined increase the risk for childhood obesity $^{(19,20)}$. Conversely, other family behaviours, such as family meal times, have been positively linked to higher dietary quality in young children and to reduced risk for being overweight ${ }^{(21-24)}$.

The associations among food insecurity, household eating patterns and food consumption practices are understudied among AI reservation populations, particularly given the important linkages to obesity and diabetes disparities. The present paper reports findings from a study among 425 heads of households within families raising 0-5-year-old children and living in four Southwestern reservation communities. Its purpose is to describe sociodemographic factors, family eating patterns and consumer practices associated with food insecurity among AI families with young children. We hypothesized that respondents who report higher food insecurity will have larger families, be younger in age, report poorer household eating patterns, be less likely to visit grocery stores and/or food banks, be more likely to visit convenience stores and fastfood restaurants and be more likely to identify challenges with providing desired foods for the family. Ultimately, we hope this information will inform policy and intervention for prevention of hunger and promotion of nutrition among AI communities.

\section{Methods}

\section{Study design}

A cross-sectional survey was administered to participants of an existing service project called 'Menu for Life'. The Menu for Life service project began in January 2010 to deliver emergency foods and resources to AI families with children aged 0 to 5 years. Services included educational information about nutrition, a list of food resources in the community and a package of non-perishable foods.
Families were referred for Menu for Life services by tribal social service providers or contacted Menu for Life to attain services directly after exposure to local advertisements. Menu for Life delivered food and educational information to families via centralized pick-up locations or directly to individual homes. A voluntary research component consisting of a household survey was added to this existing service project to assess food insecurity and food choices of participating families.

\section{Study setting}

The study took place in four Southwestern reservation communities, representing four different tribes, located in Arizona and New Mexico. The population of participating communities ranged from 5000 to 15000 .

\section{Study implementation}

AI study staff recruited, consented and administrated the survey to a convenience sample of participants receiving Menu for Life services who voluntarily enrolled in the research component. Eligible participants included adult ( $\geq 18$ years) male and female heads of household with children 0-5 years old living in one of the four study sites.

Study staff approached individuals as they arrived at the site of service delivery and administered a brief recruitment script. Upon expressing interest in the study, staff screened participants for eligibility and administered oral or written consent, depending on that community's preference. Participants completed a survey (see 'Measures' section below) that took approximately $20 \mathrm{~min}$ to complete. The survey was administered prior to receipt of Menu for Life services, so responses were not biased by receipt of services, and provision of services was not contingent on consenting to the study. To protect participants' confidentiality, the survey was self-administered in a private location. In cases of low literacy or trouble with English language, study staff administered the survey orally and translated as appropriate to participants. Surveys were administered between January and December 2010.

The study was coordinated and directed by the Johns Hopkins Center for American Indian Health. Study approvals were received from the Phoenix Area Indian Health Service Institutional Review Board, the Johns Hopkins University Institutional Review Board and all relevant participating Tribal Health Board and Council approving bodies. Permission to publish the present findings was also received from all participating Tribal Health Boards and Councils.

\section{Measures}

We collected two primary outcome measures of food insecurity levels: adult food insecurity and child food insecurity. The adult food insecurity measure was adapted from the 2005 National Health and Nutrition Examination Survey Food Security Module ${ }^{(1)}$ and consisted of five questions about food availability (e.g. 'In the last $30 \mathrm{~d}$, did 
you skip a meal because your family didn't have enough money for food?'). Following the standardized scoring guidelines for this module, if participants responded affirmatively to at least four of the five questions, they were classified as being 'food insecure', while the remaining participants were classified as being 'food secure'. The children's food insecurity measure was adapted from the US Department of Agriculture 2008 Household Food Security Survey Children's Module ${ }^{(25)}$ and consisted of eight questions about food availability for the young child/children in the household (e.g. 'In the last 12 months, did your child ever not eat for a whole day because there wasn't enough money for food?'). If participants responded affirmatively to at least five of the eight questions, they were classified as having 'food insecure' young children, while the remaining participants were classified as having 'food secure' young children. Adaptations to the original measures were very minor and consisted primarily of slight adjustments to wording and/or formatting to maximize comprehension among respondents. The survey questions were pre-tested with local staff members and community members of different ages and education levels to assure comprehension.

Given their potential associations with childhood obesity risk ${ }^{(21,26,27)}$, two household eating patterns were selected to be modelled as secondary outcomes: availability of healthy foods in the home and frequency of family meals. The availability of healthy foods in the home was measured using questions from Project $\mathrm{EAT}^{(27)}$. This index variable was divided into tertiles, and the top tertile represented the families with the highest levels of healthy foods available (i.e. 'frequently' had healthy foods available in the home). The frequency of family meals (in which all household members ate together) was gathered using a continuous (count) measure. This variable was dichotomized into binary format: at least one family meal daily $v$. less than one family meal daily.

We also measured respondents' experiences with different commercial and community food sources using a series of continuous (count) measures within a specific reference time frame. Respondents' frequency of food obtainment from each of these sources was dichotomized for analysis (i.e. visited grocery store more than once in past month, ever visited food bank, purchased food from convenience store at least once in past week, and purchased food from fast-food restaurant at least once in past week).

Measured background characteristics included study site (de-identified here, for tribal confidentiality purposes) and respondents' sex, age, number of children and household size. Participants' challenges to providing food for their families were gathered via a series of questions with multiple response options.

\section{Data management and analysis}

Data were entered at study sites into a secure web-based data management system and exported regularly for quality assurance checks and validation. Data analyses were conducted using the statistical software package Stata IC $11 \cdot 1$ (StataCorp). Data were tabulated to summarize respondents' background characteristics, reported challenges to providing food for their households, consumption of commercial and community food sources, and overall adult and child food insecurity. The top three cited challenges that respondents identified to providing food for their households (transportation, food costs and food preparation time) were examined in greater depth in subsequent regression modelling.

We used multivariate regression techniques to examine associations of caregiver characteristics, food consumption practices and reported challenges with two sets of outcomes: (i) adult and child food insecurity; and (ii) household eating patterns. The food insecurity measures served as both primary outcome measures and as potential predictors of the study's secondary outcomes (i.e. household eating patterns). We calculated relative risks (RR) for food insecurity and household eating patterns, and their associated 95\% confidence intervals, using modified Poisson regression with robust variance estimation. This regression technique is considered the optimal approach for cross-sectional analysis of relatively frequent outcomes ${ }^{(28)}$. The relative risks presented here represent the ratio of the probability of an outcome occurring in groups that were exposed $v$. unexposed to particular risk or protective factors. Given similar results for the number of children in the household and the total household size, we present only the number of children in final regression models.

\section{Results}

\section{Summary of descriptive characteristics}

A total of 425 respondents completed the survey. Demographic characteristics are summarized in Table 1. The majority of respondents were female (84\%) and responsible for food purchasing in their respective households (75\%). Almost all were the parent of a young child (92\%), with the remaining respondents being grandparents $(5 \%)$ or another relative $(3 \%)$ to a young child. The mean age of participants was $36 \cdot 2$ years (SD $14 \cdot 2$, median 34 , range $15-79$ years). Many lived in large households (six or more people, 46\%) and most had households with two to three children (51\%).

Almost one-half (45\%) of respondents were classified as adult food insecure and nearly one-third (29\%) had children in their homes who were food insecure. Only $28 \%$ reported that their households frequently had healthy foods available. Approximately 58\% of respondents reported having at least one family meal daily, with the remaining $42 \%$ never or rarely having family meals. Approximately $80 \%$ of respondents had visited a grocery store more than once in the previous month, and $44 \%$ 
Table 1 Description of Menu for Life survey participants from four Southwestern American-Indian reservation communities, 2010 ( $n$ 425)

\begin{tabular}{|c|c|c|}
\hline Caregiver characteristic & $n$ & $\%$ \\
\hline \multicolumn{3}{|l|}{ Sex of respondent } \\
\hline Male & 70 & $16 \cdot 5$ \\
\hline Female & 355 & $83 \cdot 5$ \\
\hline Responsible for purchasing food for household & 320 & $74 \cdot 5$ \\
\hline \multicolumn{3}{|l|}{ Respondent type } \\
\hline Parent & 391 & $92 \cdot 0$ \\
\hline Grandparent & 23 & $5 \cdot 4$ \\
\hline Other relative & 11 & $2 \cdot 6$ \\
\hline \multicolumn{3}{|l|}{ Age group } \\
\hline$<25$ years & 110 & $26 \cdot 1$ \\
\hline $25-34$ years & 107 & $25 \cdot 4$ \\
\hline $35-44$ years & 97 & $23 \cdot 0$ \\
\hline$\geq 45$ years & 107 & $25 \cdot 4$ \\
\hline \multicolumn{3}{|l|}{ Household size } \\
\hline$\leq 3$ people & 55 & $13 \cdot 0$ \\
\hline 4 or 5 people & 174 & $41 \cdot 0$ \\
\hline$\geq 6$ people & 195 & $46 \cdot 0$ \\
\hline \multicolumn{3}{|l|}{ Number of children } \\
\hline 1 & 77 & $18 \cdot 1$ \\
\hline 2 or 3 & 215 & $50 \cdot 6$ \\
\hline$\geq 4$ & 133 & $31 \cdot 3$ \\
\hline \multicolumn{3}{|l|}{ Food insecurity levels } \\
\hline \multicolumn{3}{|l|}{ Adult } \\
\hline Low food security (i.e. food insecurity) present among respondent & 190 & $44 \cdot 7$ \\
\hline Moderate to high food security present among respondent & 235 & $55 \cdot 3$ \\
\hline \multicolumn{3}{|l|}{ Child } \\
\hline Low food security (i.e. food insecurity) present among child/children in household & 124 & $29 \cdot 2$ \\
\hline Moderate to high food security present among child/children in household & 301 & $70 \cdot 8$ \\
\hline \multicolumn{3}{|l|}{ Household eating patterns } \\
\hline Frequently have healthy foods available in the home & 120 & $28 \cdot 2$ \\
\hline Have at least one family meal daily & 222 & $58 \cdot 1$ \\
\hline \multicolumn{3}{|l|}{ Food consumption practices } \\
\hline Visited grocery store $>1$ time in past month & 272 & $79 \cdot 5$ \\
\hline Ever been to food bank/food pantry & 174 & $44 \cdot 4$ \\
\hline \multicolumn{3}{|l|}{ Frequency of food consumption from gas station/convenience store in past week } \\
\hline 0 & 206 & $48 \cdot 5$ \\
\hline 1 or 2 & 124 & $32 \cdot 7$ \\
\hline $3-5$ & 44 & $11 \cdot 6$ \\
\hline$\geq 6$ & 5 & 1.5 \\
\hline \multicolumn{3}{|l|}{ Frequency of food consumption from fast-food restaurant in past week } \\
\hline 0 & 160 & $41 \cdot 4$ \\
\hline 1 or 2 & 166 & $42 \cdot 9$ \\
\hline $3-5$ & 51 & $13 \cdot 2$ \\
\hline$\geq 6$ & 10 & $2 \cdot 6$ \\
\hline \multicolumn{3}{|l|}{ Challenges and decision-making factors in providing foods wanted for family } \\
\hline Have transportation barriers (i.e. have no transport) & 125 & $29 \cdot 4$ \\
\hline Cost of food is major barrier & 199 & $46 \cdot 8$ \\
\hline Time required to prepare food is major factor & 278 & $65 \cdot 4$ \\
\hline
\end{tabular}

had ever been to a food bank or food pantry. Almost half $(46 \%)$ of respondents had consumed food from a convenience store in the past week, while 59\% had consumed food from a fast-food restaurant.

Participants cited the most frequent challenges to obtaining the foods they wanted for their families as foods being 'too expensive' (47\%) and not having transportation to reach food stores (29\%). Stores not having the right kinds of foods and stores' hours of operation were identified as barriers by relatively small proportions of the sample ( $8 \%$ and $7 \%$, respectively). The time required to prepare/cook food was viewed as a significant obstacle, with two-thirds (65\%) of participants citing this as a major factor in deciding what food they made for their children.
Respondents were also asked to identify their most significant challenges to getting food from food banks or pantries (data not shown in Table 1). Transportation (35\%) and distance to food banks/pantries (28\%) were leading barriers to food bank utilization, followed by eligibility requirements (22\%), pantries' limited hours of operation (15\%), overcrowding and long lines (10\%), types of foods available ( $8 \%$ ) and concerns about being recognized at the food bank (5\%).

Although site differences were purposely not explored in depth in the present study, it is worth noting that food insecurity rates were highest among the two most rural sites. There were no differences between sites with regard to healthy food availability, family meal frequency or transportation challenges. All regression model results 
Table 2 Associations between food insecurity and caregiver characteristics, food consumption practices and reported challenges among participants from four Southwestern American-Indian reservation communities, 2010 ( $n$ 425)

\begin{tabular}{|c|c|c|c|c|}
\hline \multirow[b]{3}{*}{ Caregiver characteristic } & \multicolumn{4}{|c|}{ Food insecurity outcomes } \\
\hline & \multicolumn{2}{|c|}{ Adult food insecurity } & \multicolumn{2}{|c|}{ Child food insecurity } \\
\hline & $\mathrm{RR}$ & $95 \% \mathrm{Cl}$ & $\mathrm{RR}$ & $95 \% \mathrm{Cl}$ \\
\hline \multicolumn{5}{|l|}{ Sex of respondent } \\
\hline Male & $1 \cdot 00$ & Ref. & $1 \cdot 00$ & Ref. \\
\hline Female & $0 \cdot 88$ & $0 \cdot 68,1 \cdot 14$ & $0 \cdot 87$ & $0 \cdot 60,1 \cdot 27$ \\
\hline Responsible for purchasing food for household ( $v$. not) & $1 \cdot 05$ & $0.81,1.36$ & $1 \cdot 01$ & $0.70,1 \cdot 43$ \\
\hline \multicolumn{5}{|l|}{ Respondent type } \\
\hline Parent & $1 \cdot 00$ & Ref. & $1 \cdot 00$ & Ref. \\
\hline Grandparent & $1 \cdot 34$ & $0.96,1.88$ & $1 \cdot 50$ & $0.92,2 \cdot 43$ \\
\hline Other relative & $1 \cdot 04$ & $0.55,1.96$ & $1 \cdot 29$ & $0 \cdot 59,2 \cdot 84$ \\
\hline \multicolumn{5}{|l|}{ Age group } \\
\hline$<25$ years & $1 \cdot 00$ & Ref. & $1 \cdot 00$ & Ref. \\
\hline $25-34$ years & $1 \cdot 24$ & $0.87,1 \cdot 77$ & $1 \cdot 16$ & $0.68,1.98$ \\
\hline $35-44$ years & $1 \cdot 61^{\star \star}$ & $1 \cdot 16,2 \cdot 24$ & $2 \cdot 13^{\star \star}$ & $1 \cdot 33,3 \cdot 40$ \\
\hline$\geq 45$ years & $1 \cdot 80^{\star \star \star}$ & $1 \cdot 31,2 \cdot 47$ & $2 \cdot 19^{\star \star \star}$ & $1 \cdot 38,3 \cdot 46$ \\
\hline \multicolumn{5}{|l|}{ Number of children } \\
\hline 1 & $1 \cdot 00$ & Ref. & $1 \cdot 00$ & Ref. \\
\hline 2 or 3 & $1 \cdot 48^{\star}$ & $1 \cdot 03,2 \cdot 12$ & $1 \cdot 25$ & $0.78,2 \cdot 00$ \\
\hline$\geq 4$ & $1 \cdot 73^{\star \star}$ & $1 \cdot 19,2 \cdot 50$ & $1 \cdot 73^{*}$ & $1 \cdot 08,2 \cdot 78$ \\
\hline \multicolumn{5}{|l|}{ Food consumption practices } \\
\hline Visited grocery store $>1$ time in past month $(v . \leq 1$ time $)$ & 0.92 & $0 \cdot 71,1 \cdot 19$ & $0 \cdot 69^{*}$ & $0.48,0.98$ \\
\hline Ever been to food bank/food pantry ( $v$. not) & $1 \cdot 08$ & $0 \cdot 88,1 \cdot 34$ & $1 \cdot 24$ & $0.92,1.68$ \\
\hline $\begin{array}{l}\text { Consumed food from gas station/convenience } \\
\text { store } \geq 1 \text { time in past week ( } v \text {. not) }\end{array}$ & $1 \cdot 06$ & $0 \cdot 84,1 \cdot 32$ & $0 \cdot 91$ & $0 \cdot 66,1 \cdot 26$ \\
\hline $\begin{array}{l}\text { Consumed food from fast-food restaurant } \\
\geq 1 \text { time in past week ( } v \text {. not) }\end{array}$ & 0.90 & $0 \cdot 72,1 \cdot 13$ & 0.93 & $0 \cdot 68,1 \cdot 28$ \\
\hline \multicolumn{5}{|l|}{ Challenges and decision-making factors ( $v$. not) } \\
\hline Transportation barriers (i.e. have no transport) & $1 \cdot 46^{\star \star \star}$ & $1 \cdot 19,1 \cdot 79$ & $1 \cdot 14$ & $0.83,1.55$ \\
\hline Cost of food is major barrier & $1 \cdot 47^{\star \star \star}$ & $1 \cdot 18,1 \cdot 82$ & $1 \cdot 65^{\star \star \star}$ & $1 \cdot 21,2 \cdot 24$ \\
\hline Time required to prepare food is a major factor & $1 \cdot 15$ & $0.91,1.44$ & $1 \cdot 18$ & $0.85,1.64$ \\
\hline
\end{tabular}

$\mathrm{RR}$, relative risk; Ref., referent category.

${ }^{\star} P<0 \cdot 05,{ }^{* \star} P<0.01,{ }^{* \star *} P<0.001$.

presented below adjusted for site as a covariate, thereby controlling for any potential confounding effects.

\section{Factors associated with food insecurity}

The associations between potential risk and protective factors and food insecurity are shown in Table 2 as relative risk ratios. Note that when modelling 'negative' binary outcomes such as food insecurity, any RR above 1.00 indicate potential risk factors while RR below 1.00 indicate potential protective factors.

Several factors were found to be significantly associated with food insecurity, but these were not consistent across adult $v$. child food insecurity. Regardless of study site or sex of respondent, older respondents were significantly more likely to have either adult or child food insecurity present in their households. Compared with respondents under age 25 years, respondents aged 35-44 years were 1.61 times more likely to be adult food insecure $(P<0 \cdot 01)$ and respondents aged $\geq 45$ years were 1.80 times more likely to be adult food insecure $(P<0 \cdot 001)$. Similar patterns, with larger magnitudes of associations, were seen for these age groups and the likelihood of child food insecurity. The likelihood of adult food insecurity also increased as the number of children in the household increased $(\mathrm{RR}=1.48$ for two or three children $(P<0.05)$ and $\mathrm{RR}=1.73$ for four or more children $(P<0 \cdot 01)$, as compared with households with only one child). Significantly higher likelihoods of child food insecurity were seen only in households with four or more children $(\mathrm{RR}=1 \cdot 73, P<0.05)$.

Consumption of food from food banks, gas station/ convenience stores or fast-food restaurants was not significantly associated with food insecurity levels. Having visited the grocery store at least once in the last month was associated with less child food insecurity $(\mathrm{RR}=0.69$, $P<0 \cdot 05$ ). Respondents who cited transportation barriers to food access were 1.46 times more likely to be adult food insecure than respondents who did not have transportation barriers $(P<0 \cdot 001)$. Transportation barriers were not, however, significantly associated with child food insecurity. Respondents who cited costs of food as a major barrier were significantly more likely to have both adult $(\mathrm{RR}=1.47$, $P<0 \cdot 001)$ and child food insecurity $(\mathrm{RR}=1 \cdot 65, P<0 \cdot 001)$, while food preparation time was not a significant risk factor for either child or adult food insecurity.

\section{Factors associated with bousebold eating patterns}

Table 3 summarizes associations between potential risk and protective factors and household eating patterns. 
Table 3 Associations between household eating patterns, food insecurity, caregiver characteristics, food consumption practices and reported challenges among participants from four Southwestern American-Indian reservation communities, 2010 ( $n$ 425)

\begin{tabular}{|c|c|c|c|c|}
\hline \multirow[b]{3}{*}{ Caregiver characteristic } & \multicolumn{4}{|c|}{ Household eating patterns } \\
\hline & \multicolumn{2}{|c|}{$\begin{array}{l}\text { Frequently have healthy foods } \\
\text { available in the home }\end{array}$} & \multicolumn{2}{|c|}{$\begin{array}{l}\text { Have at least one } \\
\text { family meal daily }\end{array}$} \\
\hline & $\mathrm{RR}$ & $95 \% \mathrm{Cl}$ & $\mathrm{RR}$ & $95 \% \mathrm{Cl}$ \\
\hline \multicolumn{5}{|l|}{ Sex of respondent } \\
\hline Male & $1 \cdot 00$ & Ref. & $1 \cdot 00$ & Ref. \\
\hline Female & $1 \cdot 37$ & $0 \cdot 85,2 \cdot 21$ & 1.06 & $0 \cdot 83,1 \cdot 34$ \\
\hline Responsible for purchasing food for household ( $v$. not) & $1 \cdot 37$ & $0 \cdot 92,2 \cdot 04$ & 1.05 & $0 \cdot 85,1 \cdot 29$ \\
\hline \multicolumn{5}{|l|}{ Respondent type } \\
\hline Parent & $1 \cdot 00$ & Ref. & $1 \cdot 00$ & Ref. \\
\hline Grandparent & $0 \cdot 76$ & $0.35,1 \cdot 69$ & $1 \cdot 07$ & $0.73,1.56$ \\
\hline Other relative & 0.63 & $0 \cdot 18,2 \cdot 25$ & $1 \cdot 22$ & $0 \cdot 81,1 \cdot 84$ \\
\hline \multicolumn{5}{|l|}{ Age group } \\
\hline$<25$ years & $1 \cdot 00$ & Ref. & $1 \cdot 00$ & Ref. \\
\hline $25-34$ years & $0 \cdot 72$ & $0 \cdot 50,1 \cdot 05$ & 0.99 & $0 \cdot 80,1 \cdot 22$ \\
\hline $35-44$ years & $0.57^{\star \star}$ & $0.37,0.86$ & 0.97 & $0 \cdot 77,1 \cdot 21$ \\
\hline$\geq 45$ years & $0 \cdot 45^{\star \star}$ & $0 \cdot 28,0 \cdot 71$ & $0 \cdot 75^{\star}$ & $0.57,0.98$ \\
\hline \multicolumn{5}{|l|}{ Number of children } \\
\hline 1 & $1 \cdot 00$ & Ref. & $1 \cdot 00$ & Ref. \\
\hline 2 or 3 & 0.96 & $0 \cdot 65,1 \cdot 41$ & $1 \cdot 25$ & $0.94,1.66$ \\
\hline$\geq 4$ & $0 \cdot 63^{*}$ & $0 \cdot 39,1 \cdot 00$ & $1 \cdot 25$ & $0.93,1.68$ \\
\hline \multicolumn{5}{|l|}{ Food consumption practices } \\
\hline Visited grocery store $>1$ time in past month $(v . \leq 1$ time) & $1 \cdot 02$ & $0.66,1.59$ & 0.85 & $0.67,1.06$ \\
\hline Ever been to food bank/food pantry ( $v$. not) & $0 \cdot 74$ & $0.53,1.03$ & $1 \cdot 11$ & $0.93,1.32$ \\
\hline $\begin{array}{l}\text { Consumed food from gas station/convenience } \\
\text { store } \geq 1 \text { time in past week ( } v \text {. not) }\end{array}$ & $1 \cdot 16$ & $0 \cdot 83,1 \cdot 61$ & $0 \cdot 83^{*}$ & $0.69,0.99$ \\
\hline $\begin{array}{l}\text { Consumed food from fast-food restaurant } \\
\geq 1 \text { time in past week ( } v \text {. not) }\end{array}$ & 0.95 & $0 \cdot 69,1 \cdot 33$ & $0 \cdot 76^{\star \star}$ & $0.63,0.90$ \\
\hline \multicolumn{5}{|l|}{ Challenges and decision-making factors ( $v$. not) } \\
\hline Transportation barriers (i.e. have no transport) & $0 \cdot 91$ & $0 \cdot 64,1 \cdot 28$ & 0.91 & $0 \cdot 75,1 \cdot 11$ \\
\hline Cost of food is major barrier & $0 \cdot 52^{\star \star *}$ & $0.37,0.73$ & $0 \cdot 87$ & $0.73,1.03$ \\
\hline Time required to prepare food is a major factor & $1 \cdot 77^{\star \star}$ & $1 \cdot 21,2 \cdot 60$ & 0.93 & $0 \cdot 78,1 \cdot 11$ \\
\hline \multicolumn{5}{|l|}{ Household food insecurity levels } \\
\hline Adult food insecure & $0 \cdot 50^{\star \star *}$ & $0 \cdot 36,0 \cdot 71$ & $0 \cdot 70^{\star \star \star}$ & $0.58,0.84$ \\
\hline Child food insecure & $0.58^{\star \star}$ & $0.39,0.86$ & $0 \cdot 73^{\star \star}$ & $0.58,0.92$ \\
\hline
\end{tabular}

$R R$, relative risk; Ref., referent category.

${ }^{\star} P<0.05,{ }^{\star *} P<0.01,{ }^{* \star *} P<0.001$.

Note that when modelling 'positive' binary outcomes such as healthy family eating behaviour outcomes, any RR above 1.00 indicate potential protective factors while RR below 1.00 indicate potential risk factors.

Older age groups were significantly less likely to report healthy household eating patterns. Compared with respondents under 25 years of age, older respondents were approximately half as likely to have healthy foods readily available in the home $(\mathrm{RR}=0.57(P<0 \cdot 01)$ for 35-44-yearolds and $\mathrm{RR}=0 \cdot 45(P<0 \cdot 01)$ for $\geq 45$-year-olds $)$. Respondents in the oldest age group ( $\geq 45$ years) were less likely than the youngest respondents $(<25$ year olds) to have at least one family meal daily $(\mathrm{RR}=0 \cdot 75, P<0 \cdot 05)$. Having four or more children in the home was significantly associated with a lower likelihood of having healthy foods in the home (RR $=0.63, P<0.05)$, but the number of children in the home was not associated with the likelihood of having regular family meals.

Neither grocery store nor food bank utilization was associated with the likelihood of having healthy foods available in the home or regularly having family meals. Consuming food from gas stations/convenience stores or fast-food restaurants was not associated with the availability of healthy foods, but both of these behaviours were associated with a lower likelihood of regular family meals ( $\mathrm{RR}=0.83(P<0 \cdot 05)$ for convenience store foods and $\mathrm{RR}=0.76(P<0 \cdot 01)$ for fast foods $)$.

Regarding potential challenges and decision-making factors associated with household eating patterns, transportation barriers did not appear to be significantly related to the availability of healthy foods in the home or family meal frequency. Food costs and preparation time were significantly associated with the availability of healthy foods, but not with the frequency of family meals. Respondents who identified food costs as a major challenge were half as likely to frequently have healthy foods available ( $\mathrm{RR}=0.52, P<0 \cdot 001)$. Conversely, respondents who identified time to prepare food as a major decisionmaking factor were 1.77 times more likely to have healthy foods available in the home $(P<0 \cdot 01)$.

Finally, both adult and child food insecurity were significantly associated with a lower likelihood of having healthy foods available in the home $(\mathrm{RR}=0.50(P<0.001)$ for adult food insecurity and $\mathrm{RR}=0 \cdot 58(P<0 \cdot 01)$ for child 
food insecurity) and a lower likelihood of having regular family meals $(\mathrm{RR}=0 \cdot 70(P<0 \cdot 001)$ for adult food insecurity and $\mathrm{RR}=0.73(P<0 \cdot 01)$ for child food insecurity $)$.

\section{Discussion}

\section{Summary offindings}

Among this sample of 425 AI families from four Southwestern reservation communities, food insecurity rates were very high (45\% adult food insecurity and 29\% child food insecurity). These rates represent approximately three times the levels seen in the general US population ${ }^{(29)}$. This finding is consistent with other studies that have found a significant disparity in food insecurity rates between $\mathrm{AI}$ and non- $\mathrm{AI}^{(3)}$, and reflects the vulnerability of families seeking services via the Menu for Life service project. Respondents identified the following three factors as the primary obstacles to providing desired foods for their families: (i) the time required to prepare food; (ii) the cost of food; and (iii) lack of transportation. It is important to ask if or how these determinants are driving reliance on packaged, convenience and fast foods in these rural reservation communities. Nearly half (46\%) of respondents purchased food from a gas station or convenience store within the past week and over half (59\%) consumed food from a fast-food restaurant within the past week. Reliance on fast foods, which are sometimes cheaper than fresh food options, is associated with a reduction in diet quality, increased intake of energy-dense foods and increased daily kilojoules - all factors in the diabetes epidemic for $\mathrm{AI}^{(30)}$. The $28 \%$ of respondents who indicated that they frequently have healthy foods available in their homes were considerably less likely to identify cost as a major barrier. Finally, the fact that only $58 \%$ of respondents in the present study reported having at least one family meal daily - and that these were less likely to be the food-insecure families - provides some clues to obesity prevention. Research has shown positive associations between family meal times and higher dietary quality in young children and reduced risk for being overweight $^{(21-24)}$.

We hypothesized that respondents who reported higher food insecurity and poorer household eating patterns would have larger household sizes and be younger in age. Larger household size was associated with increased food insecurity and worse eating patterns. Contrary to our initial hypothesis, older respondents were more likely than younger respondents to be at risk for both food insecurity and poorer eating patterns, even after adjusting for household size. Respondent type (e.g. parent, grandparent or other relative) was not associated with any of the food insecurity or household eating patterns, so it appears to be age and not respondent type that is driving the association.

We also hypothesized that respondents who reported higher food insecurity and less healthy household eating patterns would be less likely to visit grocery stores and/or food banks, more likely to visit convenience stores and fast-food restaurants, and more likely to identify challenges with providing desired foods for the family. Only some of these associations were statistically significant. Factors associated with food insecurity included transportation barriers, concerns about high costs of foods and fewer visits to grocery stores. Utilization of food bank/food pantry services was not associated with food insecurity or household eating patterns. Having recently visited a convenience store or fast-food restaurant was associated with some household eating patterns (i.e. less likely to have daily family meals), but not others (i.e. availability of healthy foods in the home). Costs and preparation time of foods were associated with availability of healthy foods, but not family meal frequency. Transportation barriers were not associated with either household eating pattern.

Our final hypothesis was that food-insecure families would experience less healthy household eating patterns than food-secure families. This hypothesis was supported: among this sample, both adult and child food insecurity were associated with less availability of healthy foods in the home and less likelihood of daily family meals. This finding adds to the limited research about the context of food insecurity specifically among AI families and the risks of food insecurity to the obesity and diabetes epidemic.

\section{Study limitations and future research}

Limitations of our study include the cross-sectional methodology of the survey and our subsequent inability to make causal and/or temporal associations between predictor and outcome variables. Future research should include in-depth qualitative methods to better understand how decision-making factors influence household eating patterns and how household eating patterns and food insecurity influence each other. Further research is also needed to develop measures of food behaviours specific to AI populations. For example, while several survey components used in the present study (e.g. US Department of Agriculture Module) have been widely utilized across multiple age groups and populations, others (e.g. Project EAT questions) have primarily been used among adolescent, non-AI populations and may not optimally capture food behaviours in the participating communities. Findings are also somewhat limited by the sample selected. The survey was administered to household heads receiving community food services, indicating their increased risk. While the select nature of the sample may result in overestimation of food insecurity levels as compared with the participating communities as a whole, the associations between food insecurity levels, household eating patterns and risk and protective factors remain important - particularly given the variability in food insecurity seen in the sample. 
Associations between food insecurity and caregivers' age indicate a need for more research among AI communities where older family members often care for multiple generations within their home and may face unique challenges. While our study found that older respondents were at greater risk for food insecurity, national data indicate that households with elderly residents have lower food insecurity rates ${ }^{(2)}$. Food insecurity among the elderly is of special concern because elderly persons experience unique health risks and are more vulnerable to the consequences of undernutrition and food insecurity ${ }^{(31)}$.

\section{Implications for intervention development}

The high levels of food insecurity reported here substantiate the urgent need for effective interventions among AI reservation communities, particularly given the health consequences of food insecurity ${ }^{(14,32-40)}$. Specific results related to risk and protective factors have important implications for future intervention development, including the need to address challenges to accessing healthy food such as expense, limited transportation and concerns about food preparation time. Results also indicate a need for more services targeted to older household heads and larger households. Several innovative intervention models for addressing hunger may be particularly relevant to AI reservation communities. Food delivery programmes, community-based farmers' markets or mobile grocery stores with education outreach components have the potential to overcome several of the challenges to obtaining healthy foods identified by this sample. Taking care to include specific solutions for older individuals, mobile grocery stores could also incorporate multiple visiting sites or a home-delivery option for those unable to leave their homes. Another solution with considerable potential in rural areas is food production via community or school-based gardens. Gardening helps guarantee food security in times of need, provides an increased variety of fruit and vegetables, and provides a regular supply of food which can be used and sold for profit ${ }^{(41)}$, as well as positively impacting a community's psychological and social well-being ${ }^{(42)}$. As it relates to AI communities, community and school gardens provide the opportunity to restore traditional agricultural and cultural practices. High levels of consumption of convenience store foods in this sample also warrant exploration of store-based interventions. Programmes including prioritization of shelf space, stocking of fresh produce and product signage/labelling have been shown to hold promise in increasing the purchase and consumption of healthy foods ${ }^{(43,44)}$. Specific to utilization of food banks, a number of challenges were identified that should be taken into consideration in future programmes and policies on reservations. Examples include eligibility issues, transportation barriers, overcrowding/long lines, confidentiality, as well as the location and operating hours of food banks. Finally, greater emphasis must be placed on understanding and improving policy and structural cost solutions ${ }^{(45)}$ to addressing food insecurity among AI communities. Large federal programmes, such as WIC (Special Supplemental Nutrition Program for Women, Infants, and Children) and SNAP (Supplemental Nutrition Assistance Program), are administered through many tribal lands, but underutilization remains a problem. Action is needed to connect more families to federal nutrition programmes, simplify application procedures and decrease waiting periods in order to improve the accessibility of these resources for AI families.

\section{Acknowledgements}

Financial support for this work was provided by the Share our Strength Foundation. The authors report no conflicts of interest. B.M., N.N., J.P., K.S. and A.B. secured the funding for this project. A.B. and N.N. oversaw project management. J.P. managed tribal and human subjects' regulatory approvals. V.L., L.C., S.M., A.T. and N.N. implemented the project and managed data collection. J.P., B.M. and D.T. analysed the data. B.M., N.N., D.T. and J.P. drafted the manuscript. All authors reviewed and finalized the manuscript. The authors respectfully acknowledge the American-Indian families who participated in this study. They thank the local tribal leaders and community stakeholders who generously contributed time and wisdom to approving the study and reviewing the manuscript.

\section{References}

1. Food and Agricultural Organization of the United Nations (2010) The State of Food Insecurity in the World: Addressing Food Insecurity in Protracted Crisis. Rome: FAO.

2. Mark N, Coleman-Jensen A, Andrews M et al. (2010) Household Food Security in the United States, 2009. Economic Research Report no. ERR-108. Washington, DC: USDA, Economic Research Service.

3. Gunderson C (2008) Measuring the extent, depth, and severity of food insecurity: an application to American Indians in the USA. J Popul Econ 21, 191-215.

4. Compher C (2006) The nutrition transition in American Indians. J Transcult Nurs 17, 217-223.

5. Story M, Strauss KF, Zephier E et al. (1998) Nutritional concerns in American Indian and Alaska Native children: transitions and future directions. J Am Diet Assoc 98, 170-176.

6. Frisvold GB \& Fonte AC (2007) The Cost and Availability of Healthier Foods for the Pascua Yaqui Pueblo and the Old Nogales Highway Colonia: Community Baselines and Benefits of Mobile Markets. Tuscon, AZ: University of Arizona.

7. Pareo-Tubbeh SL, Shorty M, Bauer M et al. (2000) The Variety, Affordability, and Availability of Healthful Foods at Convenience Stores and Trading Posts on the Navajo Reservation. Shiprock, NM: Diné Community College.

8. Zephier E, Himes J, Story $M$ et al. (2006) Increasing prevalences of overweight and obesity in Northern Plains American Indian children. Arch Pediatr Adolesc Med 160, 34-39.

9. Caballero B, Clay T, Davis SM et al. (2003) Pathways: a school-based, randomized controlled trial for the prevention 
of obesity in American Indian schoolchildren. Am J Clin Nutr 78, 1030-1038.

10. Indian Health Service, US Department of Health and Human Services (2009) Trends in Indian Health 2002-2003 Edition. Washington, DC: Government Printing Office.

11. Howard BV, Lee ET, Cowan LD et al. (1999) Rising tide of cardiovascular disease in American Indians. The Strong Heart Study. Circulation 99, 2389-2395.

12. Centers for Disease Control and Prevention (2003) Diabetes prevalence among American Indians and Alaska Natives and the overall population - United States, 1994-2002. MMWR Morb Mortal Wkly Rep 52, 702-704.

13. Kunitz S (2008) Changing patterns of mortality among American Indians. Am J Public Health 98, 404-411.

14. Casey PH, Simpson PM, Gossett JM et al. (2006) The association of child and household food insecurity with childhood overweight status. Pediatrics 118, e1406-e1413.

15. Martin KS \& Ferris AM (2007) Food insecurity and gender are risk factors for obesity. J Nutr Educ Behav 39, 31-36.

16. Seligman HK, Laraia BA \& Kushel MB (2010) Food insecurity is associated with chronic disease among lowincome NHANES participants. J Nutr 140, 304-310.

17. Drewnowski A \& Specter SE (2004) Poverty and obesity: the role of energy density and energy costs. Am J Clin Nutr 79, 6-16.

18. Scheier LM (2005) What is the hunger-obesity paradox? J Am Diet Assoc 105, 883-884, 886.

19. Tanumihardjo SA, Anderson C, Kaufer-Horwitz M et al. (2007) Poverty, obesity, and malnutrition: an international perspective recognizing the paradox. J Am Diet Assoc 107, 1966-1972.

20. Bronte-Tinkew J, Zaslow M, Capps R et al. (2007) Food insecurity works through depression, parenting, and infant feeding to influence overweight and health in toddlers. J Nutr 137, 2160-2165.

21. Taveras EM, Rifas-Shiman SL, Berkey CS et al. (2005) Family dinner and adolescent overweight. Obes Res 13, 900-906.

22. Gillman MW, Rifas-Shiman SL, Frazier AL et al. (2000) Family dinner and diet quality among older children and adolescents. Arch Fam Med 9, 235-240.

23. Fulkerson JA, Neumark-Sztainer D, Hannan PJ et al. (2008) Family meal frequency and weight status among adolescents: cross-sectional and 5-year longitudinal associations. Obesity (Silver Spring) 16, 2529-2534.

24. Neumark-Sztainer D, Hannan PJ, Story M et al. (2003) Family meal patterns: associations with sociodemographic characteristics and improved dietary intake among adolescents. J Am Diet Assoc 103, 317-322.

25. Nord M, Andrews M \& Carlson S (2009) Household Food Security in the United States, 2008. Economic Research Report no. ERR-83. Washington, DC: USDA, Economic Research Service.

26. Haines J, Neumark-Sztainer D, Wall M et al. (2007) Personal, behavioral, and environmental risk and protective factors for adolescent overweight. Obesity (Silver Spring) 15, 2748-2760.

27. Widome R, Neumark-Sztainer D, Hannan PJ et al. (2009) Eating when there is not enough to eat: eating behaviors and perceptions of food among food-insecure youths. $A m J$ Public Health 99, 822-828.
28. Zou G (2004) A modified Poisson regression approach to prospective studies with binary data. Am J Epidemiol 159, 702-706

29. Nord M (2009) Food Insecurity in Households with Children: Prevalence, Severity, and Household Characteristics. Economic Information Bulletin no. EIB-56. Washington, DC: USDA, Economic Research Service.

30. Paeratakul S, Ferdinand DP, Champagne CM et al. (2003) Fast-food consumption among US adults and children: dietary and nutrient intake profile. J Am Diet Assoc 103, $1332-1338$.

31. Lee JS \& Frongillo EA Jr (2001) Factors associated with food insecurity among US elderly persons: importance of functional impairments. J Gerontol B Psychol Sci Soc Sci 56, issue 2, S94-S99.

32. Casey PH, Szeto KL, Robbins JM et al. (2005) Child health-related quality of life and household food security. Arch Pediatr Adolesc Med 159, 51-56.

33. Casey PH, Szeto K, Lensing S et al. (2001) Children in food-insufficient, low-income families: prevalence, health, and nutrition status. Arch Pediatr Adolesc Med 155, 508-514.

34. Cook JT, Frank DA, Levenson SM et al. (2006) Child food insecurity increases risks posed by household food insecurity to young children's health. J Nutr 136, 1073-1076.

35. Cook JT, Frank DA, Berkowitz C et al. (2004) Food insecurity is associated with adverse health outcomes among human infants and toddlers. J Nutr 134, 1432-1438.

36. Weinreb L, Wehler C, Perloff J et al. (2002) Hunger: its impact on children's health and mental health. Pediatrics 110, e41.

37. Alaimo K, Olson CM \& Frongillo EA Jr (2001) Food insufficiency and American school-aged children's cognitive, academic, and psychosocial development. Pediatrics 108, 44-53.

38. Olson CM (1999) Nutrition and health outcomes associated with food insecurity and hunger. J Nutr 129, 2 S Suppl., 521S-524S

39. Rose D \& Oliveira V (1997) Nutrient intakes of individuals from food-insufficient households in the United States. Am J Public Health 87, 1956-1961.

40. Murphy JM, Wehler CA, Pagano ME et al. (1998) Relationship between hunger and psychosocial functioning in low-income American children. J Am Acad Child Adolesc Psychiatry 37, 163-170.

41. Quandt SA, Popyach JB, DeWalt KM (1993) Home gardening and food preservation practices of the elderly in rural Kentucky. Ecol Food Nutr 31, 183-199.

42. Armstrong D (2000) A survey of community gardens in upstate New York: implications for health promotion and community development. Health Place 6, 319-327.

43. Gittelsohn J, Song HJ, Suratkar S et al. (2010) An urban food store intervention positively affects food-related psychosocial variables and food behaviors. Health Educ Behav 37, 390-402.

44. Gittelsohn J \& Rowan M (2011) Preventing diabetes and obesity in American Indian communities: the potential of environmental interventions. Am J Clin Nutr 93, issue 5, 1179S-1183S.

45. Harrison GG (2010) Public health interventions to combat micronutrient deficiencies. Public Health Rev 32, 256-266. 